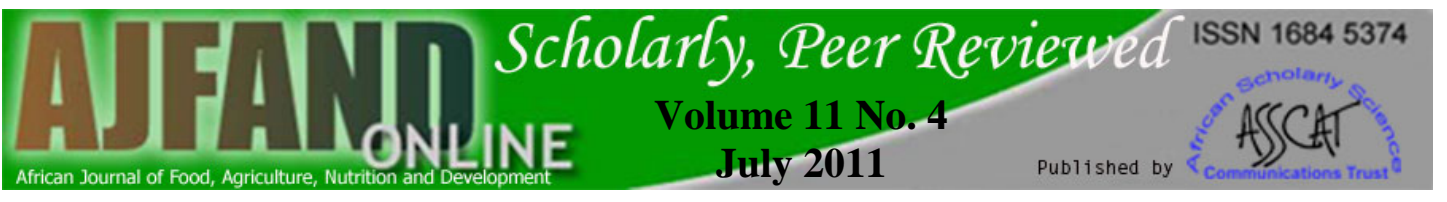

\title{
DIETARY DIVERSITY AND NUTRITIONAL STATUS OF PRE-SCHOOL CHILDREN FROM MUSA-DEPENDENT HOUSEHOLDS IN GITEGA (BURUNDI) AND BUTEMBO (DEMOCRATIC REPUBLIC OF CONGO)
}

\section{Ekesa $\mathrm{BN}^{1^{*}}$, Blomme $\mathrm{G}^{1}$ and $\mathrm{H}$ Garming ${ }^{2}$}

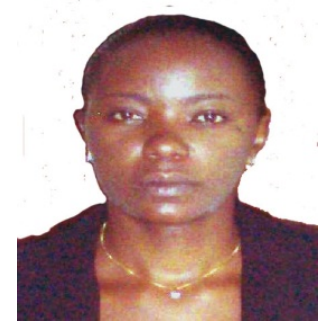

Beatrice Ekesa

*Corresponding author email: nakhauka@yahoo.comor b.ekesa@cgiar.org

${ }^{1}$ Bioversity International, Plot 106, Katalima road, P.O. Box 24384, Kampala, Uganda

${ }^{2}$ Bioversity International, Costa Rica office, CATIE, Turrialba, Costa Rica 


\section{ABSTRACT}

In sub-Saharan African countries, diets of pre-school children are predominantly based on starchy foods with little or no animal products and few fresh fruits and vegetables. A cross-sectional survey was carried out in Gitega health zone (Burundi) and Butembo health zone (Democratic Republic of Congo-DRC) with the objective of establishing dietary diversity and nutritional status of pre-school children from rural-banana dependent households. The two health zones were selected based on high dependency on bananas and plantains and the high levels of food insecurity. Through multi-stage random sampling commune/collectivity, colline/localite and villages were selected from each of the health zones; household listing was done in each of the sub-sites and systematic random sampling used to select 281 households with pre-school children (Butembo- 138 and Gitega- 143). Dietary diversity was assessed using the dietary diversity score (DDS) with a reference period of $24 \mathrm{hr}$. Anthropometric measurements were taken and Epi Info 2002 used to compute nutrition indices and results classified according to World Health Organization 2006 cut-off points. Findings showed that $48 \%$ and $42 \%$ of the children from Butembo (DRC) and Gitega (Burundi) respectively had consumed food items from less than 3 food groups. Only $7 \%$ and $29 \%$ of children from Butembo (DRC) and Gitega (Burundi), respectively had consumed highly diversified diets ( $>6$ food groups). In both countries the most popular food group was the roots, tubers and bananas group (>75\% consumption rate). The other popular food groups were; vegetables group, cereals and grains group in Gitega (Burundi) and vegetables group and legumes group in Butembo (DRC). In both countries less than 15\% of the preschool children consumed food from meat, eggs or milk groups. Stunting was the most prevalent form of malnutrition with $63.57 \%$ and $78.86 \%$ of the preschool children from Gitega and Butembo, respectively being stunted (z-scores of $\leq-2$ ), while $20 \%$ and $3.25 \%$ of children from Gitega and Burundi, respectively were wasted. The differences in levels of underweight and stunting among children from Gitega and Butembo were not statistically significant but the differences in wasting were significantly different at a $\mathrm{P}<0.05$. With the high levels of malnutrition and low dietary diversity observed among rural-Musa-dependent households in Gitega and Butembo, it is important that stakeholders work collaboratively in coming up with sustainable integrated approaches that link agriculture, nutrition and health in order to enhance the livelihoods of these communities.

Key words: Dietary diversity, Nutrition status, Preschoolers 


\section{INTRODUCTION}

In the Democratic Republic of Congo (DRC) and Burundi, bananas and plantains (Musa Spp.) play a major role in meeting the dietary needs of the people. Bananas and plantains are prepared and consumed in various forms and there is usually an affordable banana dish for every income category [1]. Results from focus group discussions (FGDs) carried out to verify the dependency on Musa Spp. showed that it was the most important staple food in Butembo (DRC) closely followed by cassava, but in Gitega (Burundi) it was second after sweet potatoes [2]. Seventy eight percent and $98.4 \%$ of the participants of the FGDs in Butembo and Gitega, respectively indicated consuming Musa-based dish daily [2]. Lack of dietary diversity is one of the severe problems among poor populations in the resource limited countries. These populations tend to rely mostly on starchy staples, their diets are monotonous, and often include little or no animal products with few fresh fruits and vegetables [3]. The diets consumed tend to be low in a number of micronutrients, and the micronutrients they contain are often in a form that is not easily bio-available, thus resulting in malnutrition [3]. The effects of malnutrition on human performance, health and survival have been the subject of extensive research for several decades and studies showed that malnutrition affects physical growth, morbidity, mortality, cognitive development, reproduction, and physical work capacity [4]. Malnutrition is an underlying factor in many diseases in both children and adults, and it contributes greatly to the disability-adjusted life years lost worldwide [4]. Whereas other developing countries are experiencing a downward trend in levels of malnutrition, Central African countries still experience an upward trend [5]. The objectives of this study were to assess the dietary diversity and nutrition status of preschool children from banana-dependent households in Butembo province of the DRC and Gitega province in Burundi.

\section{METHODOLOGY}

The countries were purposely selected based on the fact that they are the operational areas for both HealthNet Transcultural Psychosocial Organization (TPO) and the Consortium for Improving Agricultural-based Livelihoods in Central Africa (CIALCA). Gitega health zone in Burundi and Butembo health zone in the DRC were selected based on: i) being in rural set up, ii) dependency on agricultural production mainly bananas/plantains and iii) high levels of both food insecurity and malnutrition [6]. Multistage sampling was used in selection of commune/collectivity, colline/localite and villages. All the households with preschool children in the selected villages were appropriately listed. Based on secondary data on the population of preschool children in the general population, Fisher's formula was used to calculate the total sample size, which resulted in 281 households, made up of 138 in Butembo and 143 in Gitega. Systematic random sampling was then used for the selection of all the 281 households. Only households with at least one preschool child (2-5yrs) were included in the study. Formal approval for this study was obtained from the local administrations in the respective regions and verbal consent was obtained from each respondent. Data collection was carried out using structured questionnaires, which were pre-tested, modified accordingly and translated into the local language during 
administration. There was a non-response rate of $6.4 \%$ with regards to information on nutrition status but the difference did not statistically affect the results, therefore the preschool children whose nutrition status was assessed were 123 (57 boys and 66 girls) from Butembo DRC and 140 (66 boys and 74 girls) from Gitega-Burundi for a total of 263 preschool children. Dietary diversity was assessed using 24 h household dietary diversity score and validated by food frequency questionnaire. Dietary diversity scores (DDS) were created by a simple count of food groups consumed by the preschool child over the past $24 \mathrm{~h}$ preceding the interview. The food groups included in the DDS were; cereals, root/ tubers/bananas, pulses/legumes, milk and milk products, eggs, meat and offal, fish and sea foods, oil/fats, sugar/honey, fruits, vegetables and spices/condiments. With the exclusion of sugars/spices/condiments, consumption of $\leq 3$ food groups was considered as low dietary diversity; consumption of 4 and 5 food groups was medium dietary diversity, while consumption of $\geq 6$ food groups in $24 \mathrm{~h}$ was considered as high dietary diversity [7, 8]. Anthropometric measurements such as weight and height were compared to age and used to determine the nutritional status of preschool children. EPI (Epidemiology) Info 2002 version 3.5.1 software was used to compute the anthropometric indices and the results were interpreted according to World Health Organization 2006, classification (cut off points) as described in Table 1 [9].

Using SPSS version 14 software, stepwise linear regression was carried out to establish the nutrition indices most significantly influenced by dietary diversity and Pearson chi-squire tests performed to establish whether the differences observed between variables were significant at $\mathrm{p}<0.05$.

\section{RESULTS}

\section{DIETARY DIVERSITY}

\section{Diversity by food groups}

Majority of the preschool children had consumed food items from three or less food groups in the 24h preceding the survey thus indicating low dietary diversity [7]. In Butembo (DRC), $48 \%$ of the children indicated low dietary diversity with only $7 \%$ having consumed high diversified diets (Figure 1). In Gitega (Burundi), the same pattern was observed with most of the children (42\%) consuming diets low in diversity although a significantly higher proportion of preschool children in GitegaBurundi (29\%) had consumed highly diversified diets (Figure 2). 


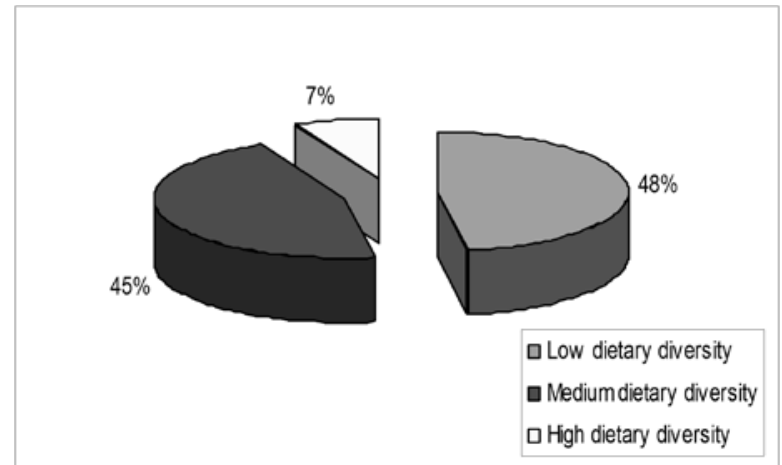

Figure 1: Dietary diversity of preschoolers in Butembo-DRC, $N=143$

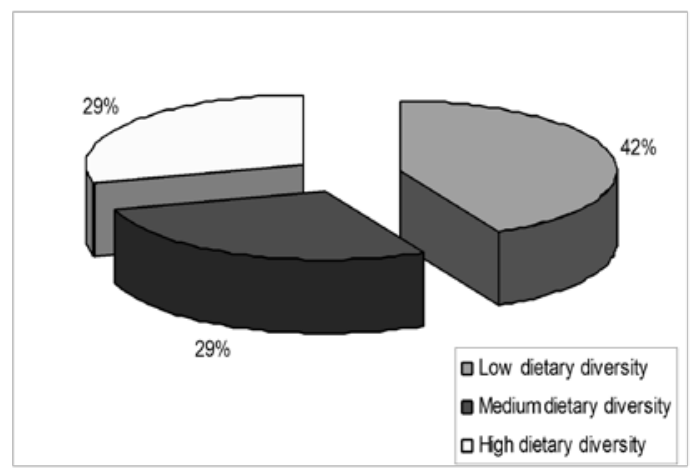

Figure 2: Dietary diversity of preschoolers in Gitega-Burundi, N=138

In Butembo-DRC, the highest consumption rate of $86 \%$ was observed in the roots/tubers/banana group followed by the vegetables group 76.5\%. In GitegaBurundi, more preschool children had consumed food items from the vegetable group (94.4\%) as compared to the roots and tubers (79.9\%). Although the cereals and grains group was popular in Gitega reporting a consumption rate of 78.5\%, in Butembo cereals and grains were not so popular and only $41.9 \%$ of the preschool children had consumed food items from this group (Table2).Vegetables available to the communities in DRC and Burundi included; amaranths, cassava leaves, bean leaves and cabbage, while the food items from the roots/tubers/banana groups available were: cassava (fresh tuber and flour), sweet potatoes, Irish potatoes, East African Highland bananas (EAHB), plantains and yams. In both Butembo and Gitega, the consumption of fats and oils was between $55 \%$ and $65 \%$ while the food groups with the lowest consumption rates were eggs, milk and milk products, meat and meat products, which recorded $\leq 5 \%$ consumption rate in both countries (Table 2 ).

\section{Food variety score}

The findings from this study showed that in both Butembo (DRC) and Gitega (Burundi), the highest number of food items consumed within the $24 \mathrm{~h}$ preceding the survey was nine; although between 4 to 6 food-items were consumed by most of the children in the DRC (58.8\%) and Burundi (59.72\%).Just as observed in number of food groups consumed, the proportion of preschool children who had consumed less 


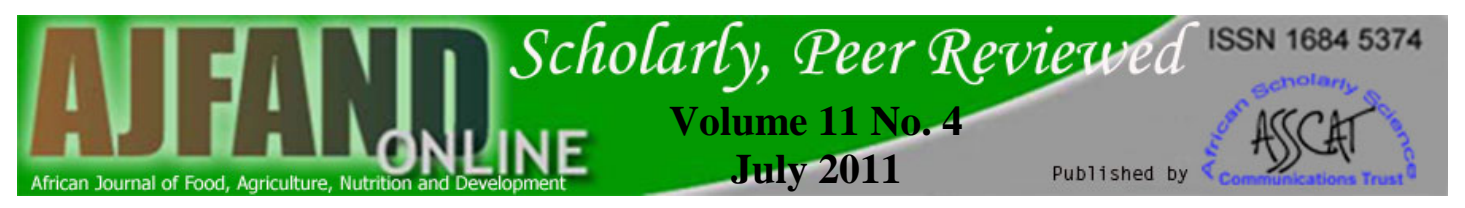

than 3 food items within the 24h preceding the survey was higher in DRC(30.15\%) as compared to the proportion from Gitega-Burundi (10.42\%)(Figure3).

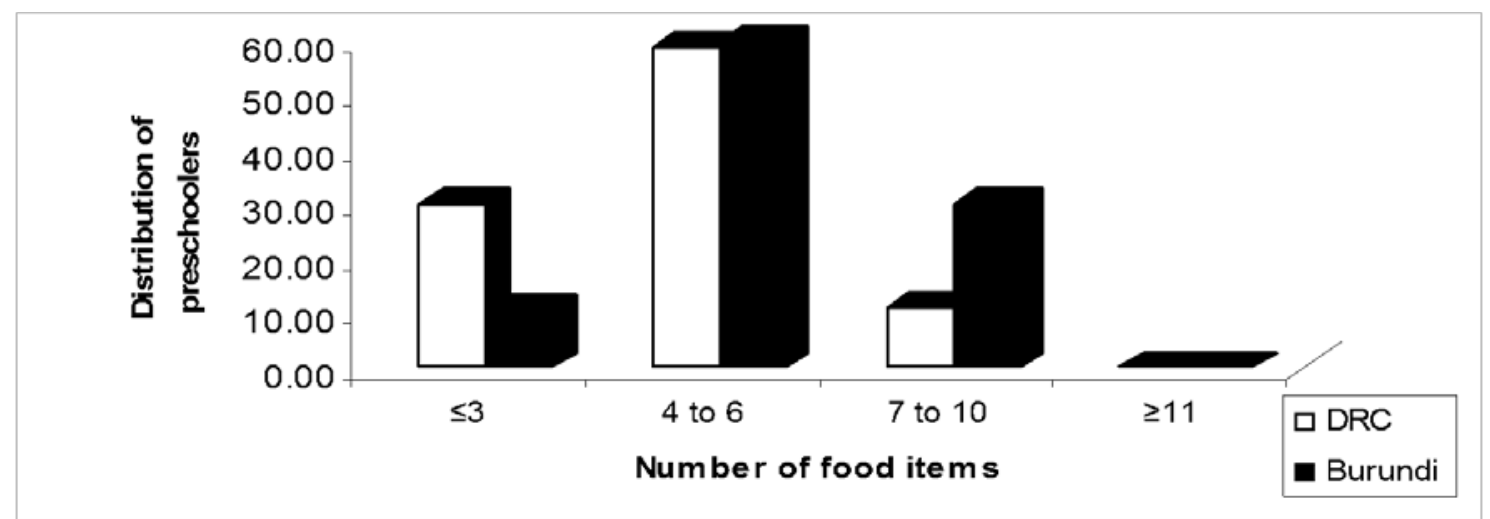

Figure 3: Level of dietary diversity of meals consumed by preschool children in DR Congo and Burundi

\section{NUTRITION STATUS}

\section{Stunting/Chronic malnutrition (Height for age)}

Findings of this survey showed that levels of stunting were very high. Only $21.14 \%$ and $36.43 \%$ of the preschool children from Butembo (DRC) and Gitega (Burundi), respectively fell within the normal range in regards to stunting ( $\geq-2 \mathrm{z}$-score). A total of $78.86 \%$ of the preschool children from Butembo had chronic malnutrition (stunting) with $40.65 \%$ severely stunted (Table 3). Levels of moderate stunting among the male and female preschool children from Butembo were 38.9\% (27.0-52.2 95\% Confidence Interval), and 36.4\% (25.8-48.4 95\% C.I), respectively. Severe stunting was $42.6 \%$ (30.3-55.8 95\% C.I) and 40.9\% (29.9-53.0 95\% C.I) among the male and the female children, respectively. The differences observed in malnutrition levels between the sexes were not statistically significant ( $\mathrm{p}>0.05)$. In Gitega (Burundi), $63.57 \%$ of the preschool children were stunted while $37.14 \%$ had severe stunting (Table 4).The prevalence of moderate stunting was 25.0\%(15.5-37.5 95\% C.I) among the male preschoolers and30.9\% (21.2-42.6 C.I) in the female preschoolers. In addition, more male children $46.4 \%$ (34.0-59.3 95\% C.I) were severely stunted as compared to the female preschoolers 26.5\% (17.4-38.0 95\% C.I). Despite the above differences the confidence intervals observed indicate no statistical significance between the sexes. Although the difference in levels of stunting among the younger preschoolers (24-41months) and older preschoolers (42-59months) from GitegaBurundi was not significantly different $(\mathrm{p}>0.05)$, those from DRC had significant differences with $69.01 \%$ of those between $24-41$ months being stunted as compared to $58 \%$ of those between $42-59$ months (Table 5).

\section{Underweight (Weight for age)}

More than $50 \%$ of the preschool children from Butembo (DRC) and Gitega (Burundi) had the right weight for age. Approximately $12.0 \%$ of the preschoolers from Butembo had z-scores below -3 indicating severe underweight (Table 3). The prevalence of moderate underweight among the male and female preschoolers was almost similar 
(25.9\% and $24.2 \%$ ), while $9.3 \%$ of boys and $7.6 \%$ of girls were severely underweight. In Burundi, those underweight were $40.71 \%$ while $18.57 \%$ were severely underweight (Table 4).The differences in underweight observed between the male and female preschool children from Gitega were not statistically significant ( $>0.05)$. Moderate underweight among the male and female preschool children was 23.0\% (14.2-34.9 95\% C.I) and 22.1\% (13.8-33.3 95\% C.I), respectively. Severe underweight was $14.8 \%$ (8.0-25.7 95\% C.I) and 11.8\% (6.1-21.5 95\% C.I) among the male and the female preschoolers, respectively. About $49.0 \%$ and $30.79 \%$ of preschoolers aged 2441 and 42-59months respectively from Gitega-Burundi were underweight. In Butembo-DRC $37.53 \%$ and $35.14 \%$ of those $24-41$ and $42-59$ months, respectively had weight for age z-scores of below -2 (Table 5).

\section{Wasting/Acute malnutrition}

Wasting was the lowest form of malnutrition observed in this study. In Butembo, all the children had the right weight for height except 3.25\% who had moderate stunting (Table 3). About5.1\% (1.7-8.9 95\% C.I) of the male children and 2.9\% (0.8-10.1 95\% C.I) of the female children were moderately wasted, but there was no case of severe wasting. In Gitega $10.71 \%$ and $9.29 \%$ had moderate and severe wasting, respectively (Table 4).The prevalence of global acute malnutrition (wasting) was not significantly different $(\mathrm{p}>0.05)$ between the male and female preschool children $(12.1 \%$ and $12.3 \%)$. The level of wasting among the younger preschoolers and older preschoolers from Gitega Burundi was almost similar but in Butembo DRC, there was no case of wasting among the older preschoolers (Table 5).

\section{Relationship between Dietary Diversity and Nutritional Status}

At $p>0.05$, there was no statistically significant relationship observed between dietary diversity and the three indices of malnutrition in DRC. In Burundi a small relationship was observed between weight for age and dietary diversity $\left(r^{2}=0.030\right)$ and Height for age and dietary diversity $\left(r^{2}=0.051\right)$.

\section{DISCUSSION}

\section{Dietary diversity}

Moving from a monotonous diet to one containing a more diverse range of foods has been shown to increase intake of energy as well as micronutrients in developing countries [10]. The observed low dietary diversity from both Gitega and Butembo in terms of food group and food items is, therefore an indication that the preschool children are not meeting their micronutrient needs. The high consumption of food items from the roots/tubers/bananas group not only confirms that diets of preschool children are predominantly based on starchy staples [8], but according to Gina et al. [10], it is also possible that the quantity of carbohydrates obtained from the roots/tubers/banana group are still not adequate to meet the macronutrient needs of the preschool children. The consumption of vegetables was also high. Following personal communications with community members, vegetables were found to be a major part of the diet of people in Butembo and Gitega. In Butembo the main vegetable is cassava leaves, which is a major relish locally known as 'sombe' usually accompanying a hard paste made from cassava flour and locally called 'ugali' made 
from cassava flour. In Gitega the main vegetable was amaranth leaves; these were either boiled separately or added to boiling bananas a few minutes before the food was ready. The high vegetable consumption has also been observed in other studies, for example a survey carried out in western Kenya observed a $100 \%$ consumption of vegetables [11]. However, the western Kenya survey was conducted during a reference period of 7 days, which is a relatively longer period when compared to the 24h used in this study, hence the 100\% consumption observed [11]. Despite the high consumption of vegetables it is likely that the nutrients in the vegetables are not bioavailable due to poor cooking methods that mostly involve boiling for prolonged periods and minimal use of fats and oils (58.9\%). It is, therefore probable that most of the water soluble vitamins such as vitamin $\mathrm{C}$ and the B-complex are lost during the cooking process and the fat soluble vitamins like vitamin A remains unavailable to the body due limited levels of dietary fats/oils [12]. The less than 5\% consumption rate of food items from the eggs group, meat and meat products group and milk and milk products group, confirms that the diets of these rural agricultural dependent households constitute very little or no animal proteins and that the diets of a large percentage of young children are deficient in iron, vitamin A (preformed), and calcium.

A study carried out in Kenya indicated that diversity greater than five was more important for growth among children who were no longer breastfed compared to those who were still breastfed. It is, therefore, important to enhance diversity in complementary foods, especially among preschool children who are entirely dependent on complementary foods for their nutrient intakes [13]. Another study also established that an increase in dietary diversity is associated with socio-economic status and household food security [14, 15]. A 74\% level of food insecurity has been reported in DR Congo [16].Therefore, the low dietary diversity observed particularly in DRC indicates that majority of the children come from poor food-insecure households that are not able to meet the nutrient needs of households members.

\section{NUTRITIONAL STATUS}

\section{Stunting}

Stunting measures cumulative growth deficiency associated with long-term factors, including insufficient dietary intake, frequent infections, poor feeding practices over a sustained period, and low socioeconomic status of households [17].Apart from the physical effects, stunting (growth retardation) is also associated with impaired cognitive functioning. Taken as a whole, growth retardation can leave an individual physically and cognitively less able to contribute to the workforce, a significant factor that may influence productivity and overall development [18]. This makes stunting a major concern for most developing countries where overall prevalence is 32.5\% [19]. The 78.9\% and 63.6\% prevalence observed in Butembo (DRC) and Gitega (Burundi), respectively are higher than those observed in surveys carried out by other organizations in the same region. Statistical reports by UNICEF indicate that 53\% of the children below five years in Burundi were stunted, while in DR Congo the prevalence of stunting was reported to be $38 \%$ although some documents have shown that $1 / 3$ of all the children below five years in DRC are stunted [20,21]. It has also 
been reported that levels of stunting can even double in rural communities; in a study of 17 countries in Africa, stunting was more prevalent in rural areas than in urban areas. Although food production on farms is majorly in rural areas, this does not mean that rural children are better nourished. This is because equally important are safe water, adequate sanitation, access to health services and information needed by mothers and other care givers to provide children with effective care; these services are relatively less accessible in rural areas [22]. Since this study was carried out in rural agricultural-dependent households, this explains the high level of stunting observed. The compromised overall health in this population can also be backed up by the very high under-five mortality rates that have been documented in the region (DRC, 200 deaths/1000 live births and Burundi 181 deaths/1000 live births) [20, 21, 23].

Levels of stunting were higher among the younger preschool children as compared to the older preschoolers; in Butembo-DRC the difference was not significant $(p>05)$ while in Gitega-Burundi the difference was significant $(\mathrm{p}<0.05)$. This indicates that in the two countries and especially Burundi, the population has gone through prolonged periods of inadequate food. There is high possibility that food inadequacy begins even before birth since fetal growth restriction mostly caused by maternal malnutrition reduces neonatal survival and has a permanent stunting effect on postnatal growth $[24,25]$. Although findings from this study didn't show significant difference in the levels between the male and female preschool children, a previous study of children aged 6-36 months in 28 African Countries during a period of 1987 to 2002 found stunting rates higher among boys in all but four of these countries with average difference of $2.6 \%$ in stunting rates between boys and girls [22].

\section{Underweight}

Under-weight reflects achieved body mass to chronological age and is the most commonly-used nutritional indicator in defining malnutrition [17]. One official Millennium Development Goal indicator of progress towards the poverty and hunger goal is the rate of low weight for-age (Underweight) of children 0-5 years [26]. In both Gitega and Butembo, the younger preschool children 24-41months were more affected because, this is a group of children who in most cases have just stopped breastfeeding and are entirely dependent on complementary foods. It is highly possible that the complementary foods are not meeting their nutrient needs. Prevalence of illnesses in preschool children has been reported to be higher among the younger group; therefore, the high level of underweight could be due to nutrient leakage caused by various diseases. Although the level of underweight children in DR Congo (36.59\%) was lower than that observed in Burundi (40.7\%) (Table 3 and 4), these levels are still higher than that of $30 \%$ observed in a study done by United Nations World Food Program (WFP) in the same country in 2007 [16], which implies that this form of malnutrition is on the rise.

\section{Wasting}

The wasting prevalence of 3.25\% and 10.7\% observed in Butembo (DRC) and Gitega (Burundi) respectively (Table 3 and 4 ) are higher than the statistically expected prevalence of between 2-3\% and the overall global prevalence of 9.4\% [27]. Although 
the slightly lower levels of wasting among the older preschoolers (42-59months) was not significant $(p>0.05)$, the results agree with reports from other studies where wasting was analyzed with the use of WFP Food Aid as the primary source of food and older children had a borderline significant decreased risk of being wasted [18]. The same pattern was also found when WFP supplement use was included in the analysis [18].

\section{General Nutrition Status}

The observed levels of stunting, wasting and underweight are above the WHO thresholds [9], thus making them problems of public health concern. Within the populations in Burundi and DR Congo, 90 and 67\% live in rural areas, respectively and depend on agricultural activities for both food and income [28]. However, chronic poverty has been exacerbated by conflicts in the two countries, which has contributed to decreased nutritional status and quality of life. In DR Congo the people live on an estimated annual income of barely 100 US\$ per capita and according to the last FAO report, 74\% of Congolese population experience food insecurity [28]. In Burundi $72.2 \%$ of the population is estimated to be poor with $16.7 \%$ extremely poor [29]. The prolonged and high levels of food insecurity could explain the high levels of malnutrition and especially stunting observed in this study.

Although other studies have shown that important gender differences in nutrition do exist in some populations, however other reports (including this study) showed that rates of malnutrition are similar for children of both sexes [30, 31].

\section{Relationship between dietary diversity and nutritional status}

Although other studies have shown that dietary diversity is significantly associated with nutritional status indicators especially among preschool children [3, 13], the poor relationship observed between dietary diversity and stunting/underweight/wasting indicates that there is more to malnutrition than just diet especially in DR Congo. Other factors of significance to look at would be maternal factors, health care services and sanitation.

\section{CONCLUSIONS}

The diversity and quality of meals provided to preschool children in DR-Congo and Burundi is poor. Less than $30 \%$ of the preschool children from both Gitega and Butembo consume highly diversified foods. The diet of the preschool children comprise mostly roots, tubers and cereals with little and in some cases no animal proteins. The diversity of meals consumed by preschool children in DR-Congo is poorer as compared to that of preschool children in Burundi.

Malnutrition and especially under-nutrition is still a major public health problem in Burundi and DR-Congo. Stunting is the most prevalent form of malnutrition followed by underweight and wasting, which indicates that people have had food shortages for a long time. In addition, preschool children aged between 24-36months are the most vulnerable to malnutrition. Nutritional status of preschool children is not only influenced by dietary diversity but by several intertwined factors. 


\section{RECOMMENDATIONS}

The low dietary diversity and high level of malnutrition reported in the two countries indicates that continued efforts to improve dietary practices and nutritional status among vulnerable groups in rural settings of Burundi and DR-Congo are warranted.

Since studies have documented a strong relationship between agricultural biodiversity and dietary diversity [11], it is important that community members are supported in enhancing agricultural diversity through cultivation of a variety of higher yielding nutritious food crops and keeping small animals. In addition the community resource persons should be capacity builders for proper agricultural practices, nutritious dietary patterns and improved health practices. It is, therefore, necessary for line ministries: Health, Agriculture, Education and Water \& Sanitation to work in collaboration with Non-Governmental organization and research organizations to ensure that communities have access to safe water, proper medical services, affordable education and nutritionally diversified food products.

Recent literature has also pointed to the complex interaction of food insecurity and conflict, and the close association between both factors. Burundi and DR-Congo are countries that have experienced civil unrest, which has adversely affected traditional agricultural practices that enhance food production and improve livelihoods. It is, therefore important for international and national agencies to work on ensuring peace and stability in DR Congo and Burundi.

\section{ACKNOWLEDGEMENT}

The authors thank Dr. Eldad Karamura of Bioversity International Uganda office for his support during planning and implementation of this research. Dr. Piet Van Asten of the International Institute of Tropical Agriculture (IITA) and Ms. Martha Nyagaya of the International Centre of Tropical Agriculture (CIAT) are acknowledged for their technical advice during the planning phase of the research. Mr. Johnson Vincent, of Bioversity International, Montpellier France is thanked for taking his time to edit this paper. 


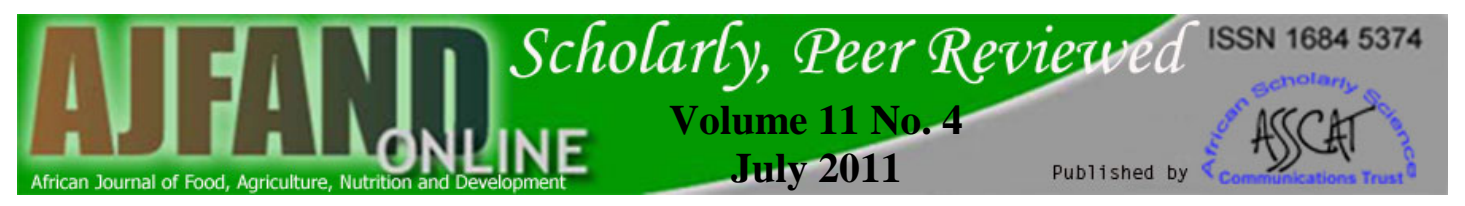

\section{Table 1: World Health Organization (WHO) classification of malnutrition in $\mathrm{z}$ - scores}

\begin{tabular}{|c|c|c|c|}
\hline \multicolumn{2}{|c|}{$\begin{array}{l}\text { Chronic malnutrition/Height for age (Stunting) \& } \\
\text { Underweight/weight for age }\end{array}$} & \multicolumn{2}{|c|}{ Acute malnutrition/weight for height (wasting) } \\
\hline $\begin{array}{l}\text { Nutrition status } \\
\text { Normal/Not stunted } \\
\text { Moderate } \\
\text { Severe } \\
\text { Total stunted } \\
\end{array}$ & $\begin{array}{l}\text { Z-scores } \\
\geq-2 \text { z-score } \\
\geq-3.0 \text { but } \iota-2.0 \\
<-3 \text { z score } \\
\iota-2 \text { z score } \\
\end{array}$ & $\begin{array}{l}\text { Nutrition status } \\
\text { None/mild } \\
\text { Moderate } \\
\text { Severe (SAM) } \\
\text { (GAM) }\end{array}$ & $\begin{array}{l}\text { Z- score } \\
\geq-2 \text { z-score } \\
\geq-3.0 \text { but }<-2.0 \\
<-3 \text { z score and/or Edema } \\
\iota-2 \text { z score and/or Edema }\end{array}$ \\
\hline
\end{tabular}

Table 2: Consumption of food items according to 12 food groups by preschool children in Butembo (DR Congo) and Gitega (Burundi)

\begin{tabular}{|l|l|l|l|l|}
\hline Food group & \multicolumn{4}{|l|}{ Distribution of households on percentage } \\
\hline & DR Congo & S.E. Mean & Burundi & S.E. Mean \\
\hline Cereals, grains and breads & 41.90 & $( \pm 0.042)$ & 78.50 & $( \pm 0.034)$ \\
\hline Roots \& tubers & 86.00 & $( \pm 0.030$ & 79.90 & $( \pm 0.034)$ \\
\hline Legumes \& pulses & 54.40 & $( \pm 0.043)$ & 35.40 & $( \pm 0.040)$ \\
\hline Milk \& milk products & 2.20 & $( \pm 0.013)$ & 4.20 & $( \pm 0.017)$ \\
\hline Eggs & 0.70 & $( \pm 0.007)$ & 0.70 & $( \pm 0.007)$ \\
\hline Meat \& meat products & 5.10 & $( \pm 0.019)$ & 1.40 & $( \pm 0.010)$ \\
\hline Vegetables & 76.50 & $( \pm 0.037)$ & 94.40 & $( \pm 0.019)$ \\
\hline Fruits & 23.50 & $( \pm 0.032)$ & 42.40 & $( \pm 0.041)$ \\
\hline Fish \& sea foods & 27.90 & $( \pm 0.039)$ & 47.90 & $( \pm 0.042)$ \\
\hline Fats \& oils & 56.60 & $( \pm 0.043)$ & 61.10 & $( \pm 0.041)$ \\
\hline Sweets \& sugars & 6.60 & $( \pm 0.021)$ & 15.30 & $( \pm 0.030)$ \\
\hline Spices and Condiments & 22.80 & $( \pm 0.036)$ & 68.80 & $( \pm 0.039)$ \\
\hline
\end{tabular}




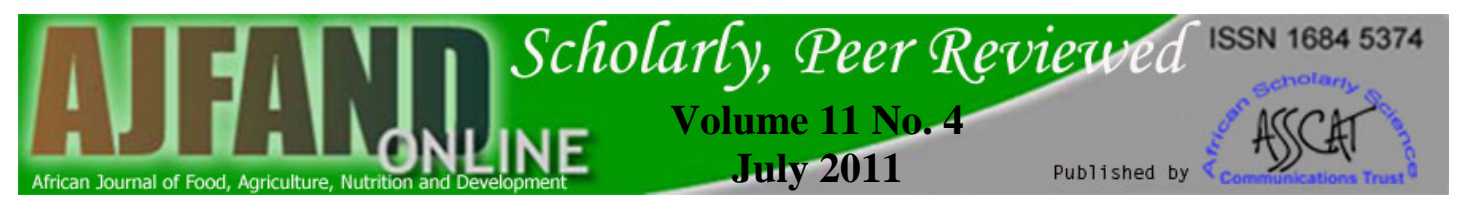

Table 3: Nutrition status of preschool children from Butembo health Zone (Democratic Republic of Congo) $\mathrm{N}=123$

\begin{tabular}{lllllll}
\hline \multirow{2}{*}{ Description of Nutrition status } & \multicolumn{2}{l}{$\begin{array}{l}\text { Height for Age } \\
\text { (Stunting) }\end{array}$} & \multicolumn{2}{l}{$\begin{array}{l}\text { Weight for Age } \\
\text { (Underweight) }\end{array}$} & \multicolumn{2}{l}{$\begin{array}{l}\text { Height for } \\
\text { Height (Wasting) }\end{array}$} \\
& Freq & $\%$ & Freq & $\%$ & Freq & $\%$ \\
\hline None/Mild malnutrition & 26 & 21.14 & 78 & 63.41 & 119 & 96.75 \\
Moderate & 47 & 38.21 & 31 & 25.20 & 4 & 3.25 \\
Severe & 50 & 40.65 & 14 & 11.38 & 0 & 0.00 \\
Total malnourished (moderate + severe) & 97 & 78.86 & 45 & 36.59 & 4 & 3.25 \\
\hline
\end{tabular}

Table 4: Nutrition status of preschool children from Gitega health Zone (Burundi) N=140

\begin{tabular}{llllllrc}
\hline \multirow{2}{*}{ Description of Nutrition status } & \multicolumn{2}{l}{$\begin{array}{l}\text { Height for Age } \\
\text { (Stunting) }\end{array}$} & \multicolumn{2}{l}{$\begin{array}{l}\text { Weight for Age } \\
\text { (Underweight) }\end{array}$} & \multicolumn{2}{l}{$\begin{array}{l}\text { Height for } \\
\text { Height (Wasting) }\end{array}$} \\
& Freq & $\%$ & Freq & \% & Freq & \multicolumn{1}{c}{$\%$} \\
\hline None /Mild malnutrition & 51 & 36.43 & 83 & 59.29 & 122 & 87.14 \\
Moderate & 37 & 26.43 & 31 & 22.14 & 14 & 10.00 \\
Severe & 52 & 37.14 & 26 & 18.57 & 4 & 2.86 \\
Total malnourished (moderate + severe) & 89 & 63.57 & 57 & 40.71 & 18 & 12.86 \\
\hline
\end{tabular}

Table 5: Prevalence of malnutrition among preschool children from Butembo (DRC) and Gitega (Burundi) by age

\begin{tabular}{llllll}
\hline & $\begin{array}{l}\text { Age in } \\
\text { Months }\end{array}$ & $\begin{array}{l}\text { Total } \\
\text { Number }\end{array}$ & $\begin{array}{l}\text { \% with Chronic } \\
\text { malnutrition }\end{array}$ & $\begin{array}{l}\text { \% with Global } \\
\text { acute malnutrition }\end{array}$ & $\begin{array}{l}\text { \%nderweight } \\
\text { Undega (Burundi) }\end{array}$ \\
& $\begin{array}{lllll}\text { 24-41months } \\
\text { Gite-59months }\end{array}$ & 62 & 69.01 & 12.33 & 49.06 \\
& & & 58.00 & 12.50 & 30.79 \\
Butembo (DRC) & 24-41months & 83 & 79.27 & 4.81 & 37.53 \\
& 42-59months & 40 & 78.95 & 0.00 & 35.14 \\
\hline
\end{tabular}




\section{REFERENCES}

1. Bioversity International. Potential Impact of Musa-based foods on micronutrient malnutrition in East Africa. Report prepared for HarvestPlus by Robert Fungo, January 2007.

2. Ekesa BNAgricultural practices, dietary diversity, Nutrition and health status of small holder communities in Gitega-Burundi and Butembo - DR Congo. Accessed on the $18^{\text {th }}$ December, 2009, from www.cialca.org.

3. Ruel MTIs diversity an indicator of food security or dietary quality? A review of measurement issues and research needs. FCND Discussion paper No. 140, International food policy research institute, Washington, DC, USA, 2002.

4. Jamalludin S Worry about diminishing biodiversity. Forest Conservation Archives.Accessed on the $21^{\text {st }}$ September 2004, from http://forests.org

5. Salah EO, Mahgoub MN and B Theodore Factors Affecting Prevalence of Malnutrition among Children under 3 years of age in Botswana. African Journal of Food. Agriculture, Nutrition and Development (AJFAND) 2006;6(1).

6. Abele S, Twine $\mathbf{E}$ and $\mathbf{C}$ Leggs Food security in Eastern Africa and the great lakes. Final report submitted to USAID on October $15^{\text {th }}$ 2007: 62 \& 68 .

7. FAO. Food insecurity. Where people live in hunger and fear starvation. The state of food insecurity in the world. Italy: 2001.

8. FANTA. Increased number of different foods or food groups consumed. Measuring household food consumption: A technical guide. FANTA, AED, 2004.

9. WHO\& UNICEF. WHO child growth standards and the identification of severe acute malnutrition in infants and children. 2009.

10. Gina LK, Maria RP, Chiara S, Guy N and B Inge Dietary Diversity Score Is a Useful Indicator of Micronutrient Intake in Non-Breast-Feeding Filipino Children. The Journal of Nutrition.2007; 137:472-477.

11. Ekesa BN, Walingo MK and MO Abukutsa-Onyango Influence of agricultural biodiversity on dietary diversity of preschool children in Matungu division, Western Kenya. African Journal of food, Agriculture, Nutrition and Development (AJFAND). 2008; 8(4).

12. Williams SR Essentials of Nutrition and Diet Therapy, $6^{\text {th }}$ edition, Mosby Toronto. 1994. 
13. Onyango A, Koski $\mathbf{K}$ and $\mathbf{K}$ Tucker Food Diversity Versus Breastfeeding Choice In Determining Anthropometric Status In Rural Kenyan Toddlers. International Journal of Epidemiology, 1998;27:484-489.

14. Hoddinott Jand YYisehacDietary diversity as an indicator of food security, FANTA, Academy for Education Development. Washington. DC. USA.2002.

15. Hatley A, Hallund J, Diarra MM and A Oshaug Food Variety, socioeconomic status and nutrition status in urban and rural areas. Koutiala (Mali). Public Health Nutrition. 2000.

16. World Food Program. Executive Brief: Burundi. Comprehensive Food Security and Vulnerability analysis (CFSVA)-2008. Accessed on the $21^{\text {st }}$ April 2009 from http://home.wfp.org/stellent/

17. El-Sayed N, Ashry GM, Leila N, Ahmed M and AS Hamdy Malnutrition among Preschool Children in Alexandre, Egypt. Journal of Health Population and Nutrition, Centre for Health and Population Research.2001.

18. Hoffman JD and L Soo- Kyung Prevalence of Wasting, but not Stunting, has Improved in the Democratic People's Republic of Korea. The American Society for Nutritional Sciences. The Journal of Nutrition2005; 452-456.

19. Aerts D, Maria de Lourdes D and RJG Elsa Determinants of Growth Retardation in Southern Brazil cad, SaudePublicia. 2004.

20. UNICEF-Burundi Nutrition and Health Statistics of 2006. Accessed on the $23^{\text {rd }}$ January 2009 from http://www.unicef.org/infobycountry/burundistatistics.html

21. UNICEF DRCongo Nutrition and Health Statistics of 2006. Downloaded on the $23^{\text {rd }}$ January 2009 from http://www.unicef.org/infobycountry/drcongostatistics.html

22. Jamison DT, Feachem RG, Makgoba MW, Bos ER, Baingana FK, Hofman KJ and OK RogoDisease and Mortality in Sub-Saharan Africa. The World Bank, Washington DC. 2006.

23. Arthur MK, Dianne JT, Sake J De Vlas, Penelope AP, William AH, Jennifer FF, John MV, Bernard LN, Robert WS and OT Feiko Prevalence and severity of Malnutrition in Preschool children in rural areas of Western Kenya. The American Journal of Tropical Medicine and Hygiene 2003;68 (4): 94-99. Accessed on the $11^{\text {th }}$ November 2009 from http://www.ajtmh.org.

24. Wu G, Bazer FW, Wallace JM and TE Spencer Intrauterine Growth Retardation; Implications for the animal Sciences. Journal of Animal Science 2006. Accessed on the $17^{\text {th }}$ November 2009 from http://jas.fass.org/. 
25. Ricci AK, Girosi F, Tarr PI, Lim Y-W, Mason C, Miller M, Hughes J, von Seidlein L, Agosti JM and RLGuerrant Reducing Stunting among Children; The potential Contribution of Diagnostics, Nature, International Weekly Journal of Science 2006; 29-38. Accesed on the $11^{\text {th }}$ November from http://www.nature.com/nature/journal

26. Government of Kenya. Nutrition Status of Children under Five, Prevalence of infections among Children below five years. Kenya Demographic Health Survey of 2003: Government Printers. Nairobi. 2004: 163-167 \& 140-146.

27. ACC/SCN. Nutrition throughout the life cycle. $4^{\text {th }}$ Report on the Worlds Nutrition Situation; Nutrition throughout the life cycle. United Nations, Standing Committee on Nutrition, Geneva. 2000:6-11.

28. FAO. Food security responses to the protracted crisis context of the Democratic Republic of Congo. Conflict research group, University of Ghent. Accessed on the $2^{\text {nd }}$ February 2009 from ftp://ftp.fao.org/docrep/fao

29. Sinkiyajako S Rapport Definitif D'enquéte De Base Du Secteur De Sante De Kibuye En Province Sanitaire De Gitega. HealthNet TPO. 2006, Burundi. Accessed on the $4^{\text {th }}$ of June 2009 from http://www.reliefweb.int/ochaburundi.

30. Midikira F Effect of Household Food Procurement Strategies on Food Consumption and Nutrition Status among Preschool Children in Sabatia Division, Western Kenya. Master of Science Thesis. Maseno University, Kenya. 2004.

31. ACC/SCN. Nutrition trends and implications for attaining the MDGs. $5^{\text {th }}$ report on the Worlds Nutrition situation; Nutrition for Improved Development Outcomes. United Nations, Standing Committee on Nutrition. Geneva. 2004: 514. 